\title{
In Memory of Dr. Hooshang Zadanfarrokh (1937-2021), a Pioneering Iranian Otolaryngologist
}

\author{
Mohammad Hossein Azizi, MD ${ }^{1 *}$; Moslem Bahadori, MD \\ ${ }^{1}$ Academy of Medical Sciences of the I. R. of Iran, Tehran, Iran \\ ${ }^{2}$ Tehran University of Medical Sciences, Alumni Office, Tehran, Iran
}

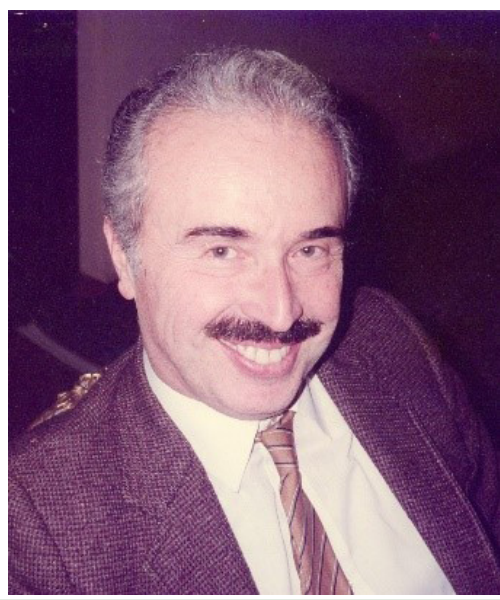

Dr. Hooshang Zadanfarrokh (1937-2021)

Dr. Hooshang Zadanfarrokh, a pioneering otolaryngologist, passed away on September 22, 2021 in Tehran due to the impact of COVID-19 (although he was cleared off it) on his pre-existing Parkinson's disease. His demise was a significant loss for his family, friends, colleagues, and his profession.

Hooshang Zadanfarrokh was born on July 31, 1937. After elementary education and completing his training at the Rahnama and Alborz High Schools, he was admitted to the Tehran University, School of Medicine, and obtained his M.D. degree in 1964. The young Dr. Zadanfarrokh continued his training at the Otolaryngology Department of Amir Aalam Hospital in Tehran and wrote his medical thesis on the "Intracranial Complications of Otitis Media", which was supervised by Dr. Nasser Moeinzadeh (1930-2015), an American trained Professor of ENT (Figure 1). ${ }^{1,2}$

Dr. Zadanfarrokh became an otolaryngologist in 1967. After several years working at a hospital affiliated with the Ministry of Economics (now called 15th Khordad Hospital, Tehran), Dr. Zadanfarrokh joined the Otolaryngology Department of Firoozgar Hospital in 1979, which was formally inaugurated in 1964 with 170 beds. At that time, the Otolaryngology Department of Firoozgar Hospital was headed by Dr. Cyrus Amiri, Dr. Zadanfarrokh was invited to join because the ENT Department was responsible for otolaryngology teaching of the medical students of Jundishapur University of Ahvaz in southern Iran. Accordingly, from 1979 until his retirement in 2004, Dr. Zadanfarrokh was actively involved in teaching ENT, taught many residents and students, and managed complicated cases and operations.

Dr. Amiri left Firoozgar Hospital in 1980 and Dr. Zadanfarrokh was promoted to the Head of the ENT Department. In 1986, Firoozgar Hospital was approved as an educational medical center affiliated to the Iran University of Medical Sciences and Dr. Zadanfarrokh was appointed as the Director of the ENT Group (Figure 2).

Dr. Zadanfarrokh was an expert otolaryngologist and a competent and always an up-to-date head and neck surgeon, especially in the fields of otologic surgeries, functional endoscopic procedure, and open rhinoplasty. In addition, Dr. Zadanfarrokh was a caring, considerate teacher and a superb mentor with high morals. He was an influential member of the "Iranian Society of

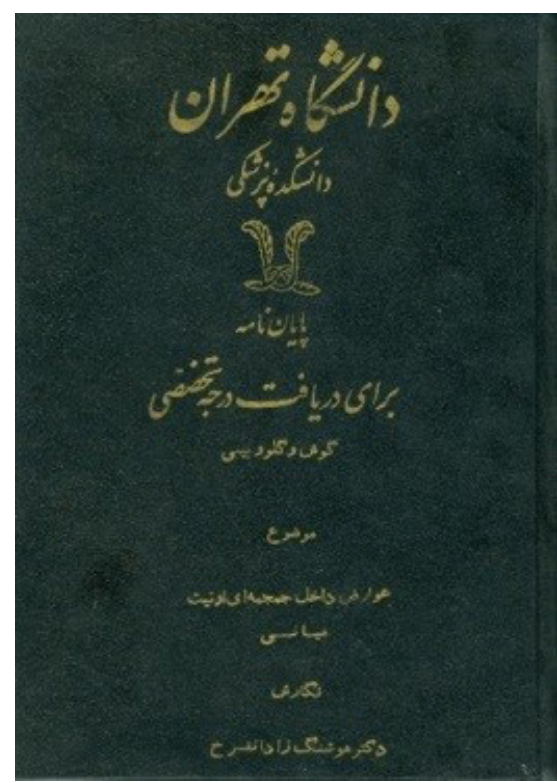

Figure 1. Dr. Zadanfarrokh ENT Thesis in 1967 Supervised by Dr. Nasser Moeinzadeh. 


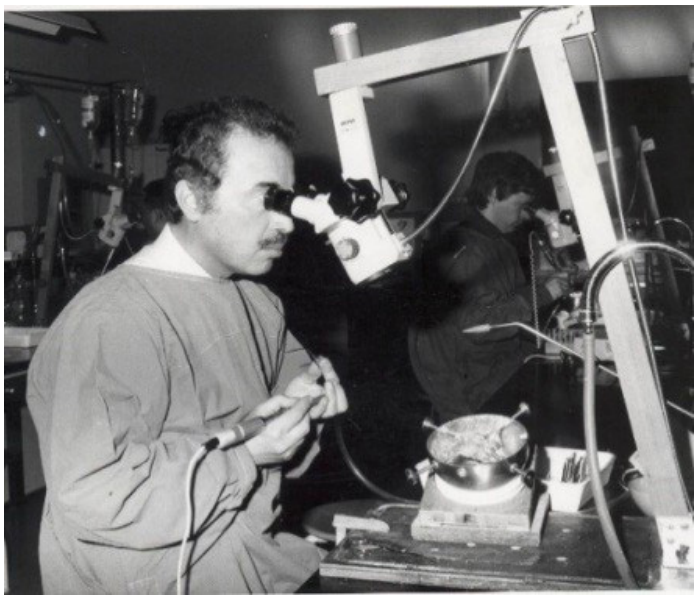

Figure 2. Dr. Zadanfarrokh in the Temporal Bone Dissection Laboratory.

otolaryngology and Head and Neck Surgery" and a founder and Vice-president of the "Rhinology Society of Iran". He actively attended many domestic and international otolaryngology seminars and workshops (Figure 3).

He was a member of the "National ENT Examination Board" of the Iranian Ministry of Health and Medical Education for around 15 years.

Dr. Zadanfarrokh married Miss Giti Nader-Isfahani in April 1962. They had two sons, Farzin and Farshid. In 2014, his younger son Farshid (1969-2014), BSc of Mathematics from the Imperial College of London, a qualified Chartered Accountant, who was a Chief Operating Officer at the Bank of America Merrill Lynch, passed away due to pancreatic cancer. Farshid's demise was most tragic for his family, and Dr. Zadanfarrokh developed Parkinson's disease. Finally, after a fruitful life and more than five decades of medical practice, he passed away on September 22, 2021 and was buried the next day in Behesht Zahra (plot 92, column 60, row 28) Tehran. $\mathrm{He}$ is survived by his wife (a retired high school teacher), Farzin (PhD of Steel Structures and an entrepreneur) and his granddaughter Xiba and grandson Kian.

In conclusion, Dr. Zadanfarrokh was a distinguished physician who was kind, generous and dedicated to his family, patients, and profession. His memory will not be forgotten, and he will always be remembered for his achievements in life by his family, friends, colleagues, and former resident trainees.
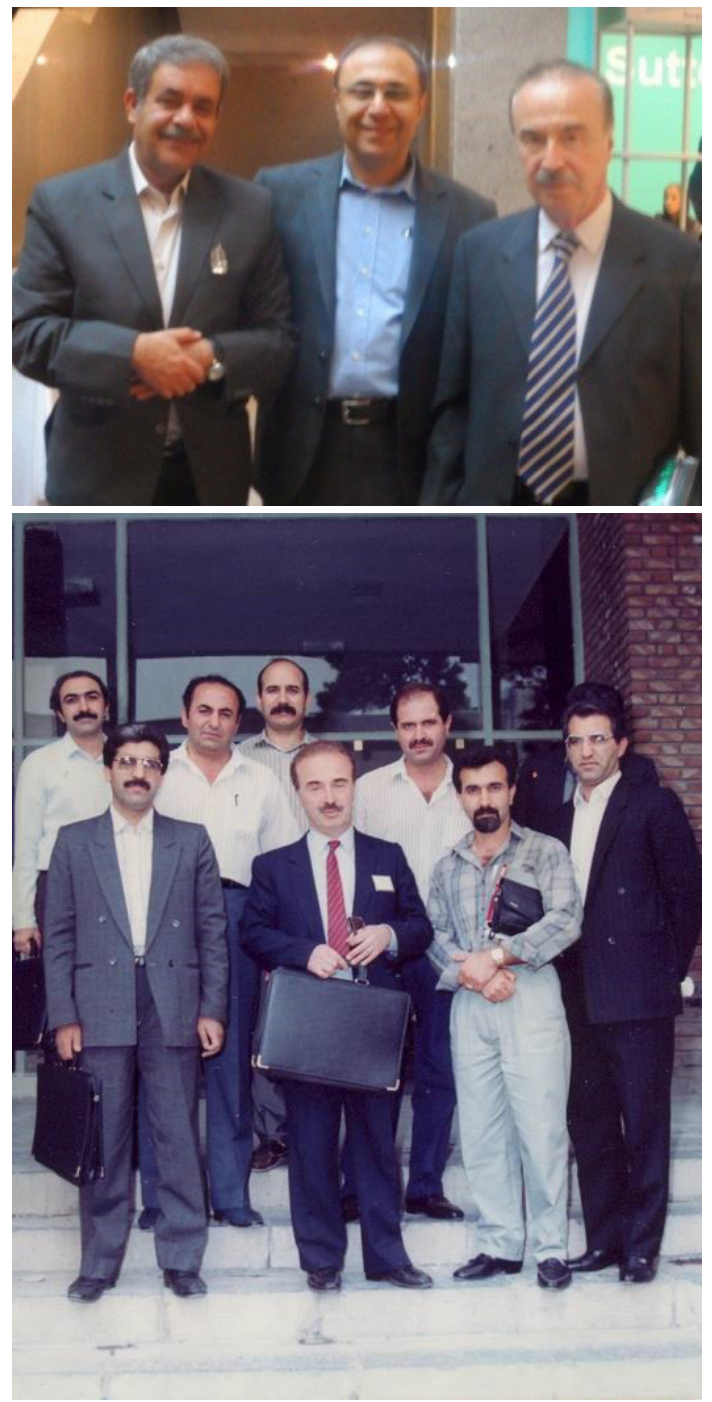

Figure 3. Dr. Zadanfarrokh and Some of His Former Otolaryngology Residents.

\section{Acknowledgement}

The authors wish to thank Mr. Farzin Zadanfarrokh for providing the background information and reviewing the draft of this article.

\section{References}

1. Azizi M. H. An interview with Professor Hooshang Zadanfarrokh \{in Persian\}, Nashrieh-e Avay Doost, Iranian Association of Ear, Nose and Throat and Head and Neck Surgery. September-October 2019:23:2-4.

2. Azizi M. H, Bahadori M. Dr. Nasser Moeinzadeh, a Pioneering Otolaryngologist in Iran. Arch Iran Med. 2015;18(10):737.

Received: September 25, 2021, Accepted: September 30, 2021, ePublished: October 1, 2021

Cite this article as: Azizi MH, Bahadori M. In memory of Dr. Hooshang Zadanfarrokh (1937-2021), a pioneering iranian otolaryngologist. Arch Iran Med. 2021;24(10):786-787. doi: 10.34172/aim.2021.117

(c) (1) 2021 The Author(s). This is an open-access article distributed under the terms of the Creative Commons Attribution License (http://creativecommons org/licenses/by/4.0), which permits unrestricted use, distribution, and reproduction in any medium, provided the original work is properly cited. 